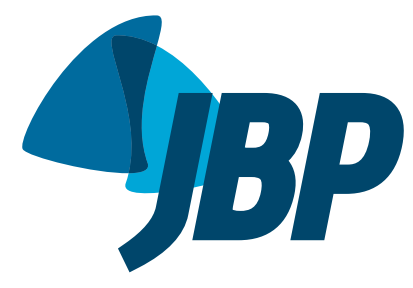

\title{
Who are the patients with tuberculosis who are diagnosed in emergency facilities? An analysis of treatment outcomes in the state of São Paulo, Brazil
}

\author{
Otavio Tavares Ranzani1,2,a, Laura Cunha Rodrigues, ${ }^{2, b}$, Eliseu Alves Waldman, \\ Elena Prina ${ }^{1, d}$, Carlos Roberto Ribeiro Carvalho ${ }^{1, e}$
}

1. Divisão de Pneumologia, Instituto do Coração - InCor - Hospital das Clínicas, Faculdade de Medicina, Universidade de São Paulo, São Paulo (SP) Brasil.

2. London School of Hygiene \& Tropical Medicine, London, United Kingdom.

3. Departamento de Epidemiologia, Faculdade de Saúde Pública, Universidade de São Paulo, São Paulo (SP) Brasil.

a. (ID) http://orcid.org/0000-0002-4677-6862

b. (iD) http://orcid.org/0000-0001-9008-660X

c. (D) http://orcid.org/0000-0001-7807-6898

d. (DD http://orcid.org/0000-0002-6937-8613

e. (iD) http://orcid.org/0000-0002-1618-8509

Submitted: 31 October 2017 Accepted: 11 February 2018

Study carried out in the Divisão de Pneumologia, Instituto do Coração - InCor - Hospital das Clínicas, Faculdade de Medicina, Universidade de São Paulo, São Paulo (SP) Brasil.

\begin{abstract}
Objective: Early tuberculosis diagnosis and treatment are determinants of better outcomes and effective disease control. Although tuberculosis should ideally be managed in a primary care setting, a proportion of patients are diagnosed in emergency facilities (EFs). We sought to describe patient characteristics by place of tuberculosis diagnosis and determine whether the place of diagnosis is associated with treatment outcomes. A secondary objective was to determine whether municipal indicators are associated with the probability of tuberculosis diagnosis in EFs. Methods: We analyzed data from the São Paulo State Tuberculosis Control Program database for the period between January of 2010 and December of 2013. Newly diagnosed patients over 15 years of age with pulmonary, extrapulmonary, or disseminated tuberculosis were included in the study. Multiple logistic regression models adjusted for potential confounders were used in order to evaluate the association between place of diagnosis and treatment outcomes. Results: Of a total of 50,295 patients, 12,696 (25\%) were found to have been diagnosed in EFs. In comparison with the patients who had been diagnosed in an outpatient setting, those who had been diagnosed in EFs were younger and more socially vulnerable. Patients diagnosed in EFs were more likely to have unsuccessful treatment outcomes (adjusted OR: $1.54 ; 95 \% \mathrm{Cl}: 1.42-1.66$ ), including loss to follow-up and death. At the municipal level, the probability of tuberculosis diagnosis in EFs was associated with low primary care coverage, inequality, and social vulnerability. In some municipalities, more than $50 \%$ of the tuberculosis cases were diagnosed in EFs. Conclusions: In the state of São Paulo, one in every four tuberculosis patients is diagnosed in EFs, a diagnosis of tuberculosis in EFs being associated with poor treatment outcomes. At the municipal level, an EF diagnosis of tuberculosis is associated with structural and socioeconomic indicators, indicating areas for improvement.
\end{abstract}

Keywords: Tuberculosis/diagnosis; Emergency treatment; Treatment outcome; Delivery of health care.

\section{INTRODUCTION}

Tuberculosis remains a common disease and a complex public health problem, particularly in low- and middle-income countries, as well as in the poorest sections of high-income countries. ${ }^{(1,2)}$ Early diagnosis and treatment are the main determinants of favorable patient outcomes and effective control, reducing the period of transmissibility. ${ }^{(1-6)}$

There are barriers to early tuberculosis diagnosis and treatment, including delays in seeking medical attention after symptom onset, in establishing a definitive diagnosis, and in initiating appropriate treatment. ${ }^{(3,5,6)}$ Several studies have examined factors associated with delayed diagnosis and treatment, including patient-related factors (e.g., age, female sex, other reasons for chronic cough, and self-perception), socioeconomic factors (e.g., social cohesion, poverty, and education), and health care system-related factors (e.g., access to primary care and tuberculosis caseload). ${ }^{(4-7)}$

The Brazilian public health care system provides universal coverage, being organized in a hierarchical and decentralized manner and providing full tuberculosis treatment free of charge. ${ }^{(8,9)}$ Tuberculosis control in Brazil has improved in recent years, the overall incidence and associated mortality rate having decreased. (2) However, Brazil remains on the list of high-burden countries and has yet to achieve all of the World Health Organization (WHO) goals for tuberculosis control, particularly those related to treatment outcomes (i.e., a treatment success rate $>$ $85 \%) \cdot(2,9,10)$ The state of São Paulo has a population of 44 million inhabitants distributed among 645 municipalities and accounts for nearly $20 \%$ of all tuberculosis cases in Brazil. Although the state of São Paulo is one of the

\section{Correspondence to:}

Otavio T. Ranzani. Laboratório de Pneumologia, Disciplina de Pneumologia, Faculdade de Medicina, Universidade de São Paulo, Avenida Dr. Arnaldo, 455, $2^{\circ}$ andar, sala 2144, CEP 01246903, São Paulo, Brasil.

Tel.: 5511 3061-7361. E-mail: otavioranzani@yahoo.com.br Financial support: Otavio T. Ranzani is the recipient of a Master's Fellowship in Public Health and Tropical Medicine from the Wellcome Trust (Grant no. $104006 / Z / 14 / Z)$ 
wealthiest in the country, it has yet to achieve the goals related to treatment success. ${ }^{(9-13)}$

Previous studies have shown that the proportions of tuberculosis cases diagnosed in a hospital setting or in emergency facilities (EFs) are high in Brazil, which might indicate lack of access to health care and delayed diagnosis. ${ }^{(3,14-19)}$ However, those studies were either single-center studies or studies conducted at the municipal level. ${ }^{(20,21)}$ To overcome these limitations, we conducted the present population-based study, the objective of which was to describe patient characteristics by place of diagnosis and determine whether the place of diagnosis is associated with treatment outcomes. A secondary objective was to determine whether structural and socioeconomic indicators are associated with the likelihood of being diagnosed in EFs at the aggregate level, in order to inform targeted public health strategies.

\section{METHODS}

\section{Population and setting}

The present study was a retrospective analysis of data from the São Paulo State Tuberculosis Control Program database for the period between January of 2010 and December of 2013. Newly diagnosed patients over 15 years of age with pulmonary, extrapulmonary, or disseminated tuberculosis were included in the study. Only new patients were included because patients with recurrent tuberculosis (relapse or reinfection) are highly expected to go through a different diagnostic process. In addition, prison inmates were excluded, as were patients diagnosed through active case finding, including those who had been diagnosed after contact tracing investigation, because of the specific circumstances associated with place of diagnosis.

All of the tuberculosis cases included in the present study were either bacteriologically confirmed or clinically diagnosed cases, in accordance with the WHO definitions. ${ }^{(22)}$

\section{Data sources}

Patient-related data were collected from an electronic health system (the TBweb database). $\cdot^{(9,23)}$ Because tuberculosis notification (including reporting of treatment initiation) is compulsory, the TBweb database includes data for all municipalities in the state of São Paulo. In addition, the São Paulo State Tuberculosis Control Program has been investing human and financial resources in the TBweb database, data accuracy and quality therefore being guaranteed. $(9,23)$

Data on the municipalities were collected from the following databases: the Brazilian Institute of Geography and Statistics database ${ }^{(24)}$; the São Paulo Sistema Estadual de Análise de Dados (SEADE, State System of Data Analysis) Foundation database(13); and the Brazilian National Ministry of Health Department of Primary Care database. (25) The São Paulo SEADE Foundation is an independent public agency, being a national referral center for analysis of socioeconomic and demographic data. ${ }^{(13)}$

\section{Indicators at the municipal level}

The following indicators were used: population size, population density, gross domestic product, per capita gross domestic product, and level of urbanization. Composite indicators were also used, including the Índice de Desenvolvimento Humano (IDH, Human Development Index)-which assesses education, life expectancy, and economic development and ranges from 0 to 1 (IDH values closer to 1 translating to greater human development)-and the Gini coefficient, which assesses inequality and ranges from 0 to 1 (a Gini coefficient of 0 indicating perfect equality and a Gini coefficient of 1 indicating maximal inequality), on the basis of data from the 2010 Census. ${ }^{(24)}$ The 2010 version of the Índice Paulista de Vulnerabilidade Social (IPVS, São Paulo State Social Vulnerability Index), developed by the São Paulo SEADE Foundation, was also used. (26) The IPVS encompasses several demographic and socioeconomic variables, such as level of education, per capita household income, age, and sex distribution. The population of each municipality was divided into the seven categories of vulnerability defined by the IPVS. In the present study, the indicator selected was the proportion of the municipal population classified as highly vulnerable (i.e., individuals in category 5 , 6 , or 7). Data from the Brazilian National Ministry of Health were used in order to assess primary care coverage (i.e., family health strategy program or equivalent) in each municipality. ${ }^{(25)}$ Other São Paulo SEADE Foundation indicators used in the present study included proportion of pregnancies with at least seven antenatal visits and infant mortality rate per 1,000 live births. ${ }^{(13)}$ All primary care indicators were obtained from mid-year values.

\section{Outcomes}

The 2013 WHO treatment outcome definitions were used, being adapted to the TBweb database definitions. $(9,22)$ The outcomes are divided into desirable outcomes (i.e., treatment success) and undesirable outcomes, the latter including treatment failure, death, loss to follow-up, and not evaluated. ${ }^{(9,22)}$

\section{Data analysis}

Continuous variables were expressed as mean \pm standard deviation or median (interquartile range), depending on their distribution. Categorical variables were expressed as absolute numbers and proportions, being compared by Fisher's exact test or the chi-square test, as appropriate.

A multiple logistic regression model was used in order to evaluate the association between place of diagnosis and unsuccessful treatment outcome. Adjusted ORs were calculated, allowing for potential confounding factors defined a priori. Patient-related factors, as well as disease- and treatment-related factors, were selected on the basis of the literature. Patient-related factors included age, sex, country of birth, self-reported ethnicity, homelessness, level of education, alcohol use, drug use, diabetes mellitus, 
mental disorder, HIV status, and immunosuppression from etiologies other than HIV infection. Disease- and treatment-related factors included place of diagnosis, chest $\mathrm{X}$-ray findings at diagnosis, microbiological status at diagnosis, initial drug regimen, and directly observed treatment. Given its importance among unsuccessful treatment outcomes, death was used as the dependent variable in a second multiple logistic regression model.

An additional analysis was performed at the municipal level. Initially, the number of cases and place of diagnosis were grouped by municipality. Subsequently, each indicator was tested in a univariate analysis as a predictor of diagnosis in EFs, the most important variables being retained in order to explain the variance in the outcome. When the same dimension was assessed by two different indicators, composite indicators were preferred over single indicators, multicollinearity being dealt with in the final model. In order to include the IPVS, which was available for all of the municipalities in the state of São Paulo, two final models were selected. All analyses were performed with the Stata statistical software package, version 13.1 (StataCorp LP, College Station, TX, USA), and the blogit command was used in order to run logistic models for grouped data at the municipal level.

\section{RESULTS}

Of a total of 62,178 patients who were diagnosed with tuberculosis between January of 2010 and January of $2013,7,027$ (11.3\%) were excluded because they were prison inmates, 3,374 (5.4\%) were excluded because they had been diagnosed through active case finding or contact tracing investigation, 696 (1.1\%) were excluded because they had been diagnosed at autopsy, and $786(1.3 \%)$ were excluded because there was no information regarding place of diagnosis. Therefore, the final sample consisted of 50,295 patients spontaneously seeking medical attention at health care units in the state of São Paulo.

The general characteristics of the patients analyzed in the present study are shown in Table 1. Most of the patients were young males. Of the sample as a whole, $55 \%$ had been diagnosed in an outpatient setting, $25 \%$ had been diagnosed in EFs, and $20 \%$ had been diagnosed in a hospital setting. In comparison with the patients who had been diagnosed in an outpatient or hospital setting, those who had been diagnosed in EFs were notably younger, the following being more common in the latter than in the former: being male, self-reporting mixed ethnicity, being homeless, using alcohol, using drugs, and having a low level of education. A diagnosis of tuberculosis during hospitalization was more common in patients with chronic disease (e.g., diabetes mellitus, HIV infection, and immunosuppression from etiologies other than HIV infection) than in those without it.

Table 2 shows the characteristics of tuberculosis and tuberculosis treatment, by place of diagnosis, among the patients analyzed in the present study. Of the patients who had been diagnosed in EFs, approximately
$80 \%$ had pulmonary tuberculosis, the prevalence of positive sputum smears and cultures being higher in those patients than in those who were diagnosed in an outpatient or hospital setting. Other forms of tuberculosis, including extrapulmonary tuberculosis and disseminated/miliary tuberculosis, were more frequently diagnosed in a hospital setting than in an outpatient setting or in EFs.

As can be seen in Table 3 and Figure 1, the place of diagnosis was associated with tuberculosis treatment outcomes ( $p<0.001)$, which were worse in the patients who had been diagnosed in EFs or in a hospital setting than in those who had been diagnosed in an outpatient setting. In addition, the proportion of loss to follow-up was higher among the patients who had been diagnosed in EFs. After adjustment for potential confounders, the likelihood of treatment failure and death was higher in the patients who had been diagnosed in EFs or in a hospital setting than in those who had been diagnosed in an outpatient setting, results that were consistent with those of a sensitivity analysis in the subgroups of HIV-positive and HIV-negative patients.

During the study period, 591 (92\%) of the municipalities in the state of São Paulo reported cases of tuberculosis. In $96(16 \%)$ of all municipalities in the state of São Paulo, more than $30 \%$ of all tuberculosis cases were diagnosed in the EFs; in 15 (2.5\%), more than $50 \%$ of all cases were diagnosed in EFs.

Table 4 shows the variables that remained in the models at the municipal level. Municipalities in which primary care coverage was higher were less likely to have tuberculosis cases diagnosed in EFs, whereas municipalities in which inequality and vulnerability were high were more likely to have tuberculosis cases diagnosed in EFs. Figure 2 shows the relationship of the $\mathrm{IDH}$, the Gini coefficient, and primary care coverage with the probability of being diagnosed in EFs, as estimated from adjusted model 1.

For illustrative purposes, we selected four municipalities. Municipality A notified 1,138 cases, being the third leading contributor to the burden of tuberculosis in the state (in absolute numbers). Of those cases, $53 \%$ had been diagnosed in EFs. Municipality $A$ has a high IDH (i.e., 0.768 ), and $21 \%$ of its population are highly vulnerable; however, primary care coverage is only $34 \%$. In municipality $B$, the proportion of cases diagnosed in EFs was $41 \%$. Although the IDH is very high (i.e., 0.814) and primary care coverage is $48 \%$ in that municipality, inequality is very high (Gini coefficient, 0.6858 ) and $36 \%$ of its population are highly vulnerable. In municipality $\mathrm{C}$, inequality is high (Gini coefficient, 0.5971 ) and 33\% of the population are highly vulnerable; however, primary care coverage is $99 \%$, and the proportion of cases diagnosed in EFs was $21 \%$. Finally, in municipality D, the proportion of cases diagnosed in EFs was 7\%, primary care coverage is $89 \%$, the IDH is high (i.e., 0.798 ), and only $8 \%$ of the population are highly vulnerable. 
Who are the patients with tuberculosis who are diagnosed in emergency facilities?

An analysis of treatment outcomes in the state of São Paulo, Brazil

Table 1. General characteristics of patients newly diagnosed with tuberculosis, by place of diagnosis, in the state of São Paulo, Brazil, in the period between January of 2010 and December of 2013. ${ }^{a}$

\begin{tabular}{|c|c|c|c|c|}
\hline Variable & $\begin{array}{l}\text { Primary care/ } \\
\text { outpatient setting } \\
\text { (n=27,415) }\end{array}$ & $\begin{array}{c}\text { EFs } \\
(n=12,696)\end{array}$ & $\begin{array}{c}\text { During } \\
\text { hospitalization } \\
\text { (n=10,184) }\end{array}$ & p \\
\hline \multicolumn{5}{|l|}{ Age, years ${ }^{b}$} \\
\hline $15.0-25.0$ & $5,009(18.3)$ & $2,676(21.1)$ & $1,500(14.7)$ & \multirow{8}{*}{$<0.001$} \\
\hline $25.1-35.0$ & $6,458(23.6)$ & 3,285 (25.9) & $2,284(22.4)$ & \\
\hline $35.1-45.0$ & $5,565(20.3)$ & $2,614(20.6)$ & $2,264(22.2)$ & \\
\hline $45.1-55.0$ & $5,047(18.4)$ & $2,123(16.7)$ & 1,906 (18.7) & \\
\hline $55.1-65.0$ & $3,122(11.4)$ & $1,239(9.8)$ & $1,200(11.8)$ & \\
\hline $65.1-75.0$ & $1,470(5.4)$ & 499 (3.9) & $614(6.0)$ & \\
\hline $75.1-85.0$ & $605(2.2)$ & $207(1.6)$ & $333(3.3)$ & \\
\hline $85.1-105$ & $125(0.5)$ & $41(0.3)$ & $78(0.8)$ & \\
\hline \multicolumn{5}{|l|}{ Sex } \\
\hline Female & $9,615(35.1)$ & $3,785(29.8)$ & $3,236(31.8)$ & \multirow[t]{2}{*}{$<0.001$} \\
\hline Male & $17,800(64.9)$ & $8,911(70.2)$ & $6,948(68.2)$ & \\
\hline \multicolumn{5}{|l|}{ Country of birth ${ }^{c}$} \\
\hline Brazil & $22,802(96.6)$ & $10,285(96.8)$ & $8,500(98.5)$ & \multirow[t]{2}{*}{$<0.001$} \\
\hline Other & $805(3.4)$ & $334(3.2)$ & $129(1.5)$ & \\
\hline \multicolumn{5}{|l|}{ Self-reported ethnicity ${ }^{d}$} \\
\hline White & $13,157(55.1)$ & $5,296(47.9)$ & $5,087(56.6)$ & \multirow{5}{*}{$<0.001$} \\
\hline Black & $2,645(11.1)$ & $1,392(12.6)$ & $1,012(11.3)$ & \\
\hline Mixed & $7,441(31.2)$ & $4,208(38.1)$ & $2,756(30.7)$ & \\
\hline Asian & $356(1.5)$ & $102(0.9)$ & $107(1.2)$ & \\
\hline Indigenous & $270(1.1)$ & $55(0.5)$ & $23(0.3)$ & \\
\hline \multicolumn{5}{|l|}{$\begin{array}{l}\text { Level of education, number of years of } \\
\text { schooling }\end{array}$} \\
\hline 0 (illiterate) & $838(3.7)$ & $360(3.6)$ & $339(4.3)$ & \multirow{6}{*}{$<0.001$} \\
\hline $1-3$ & $2,639(11.5)$ & $1,119(11.3)$ & 817 (10.5) & \\
\hline $4-7$ & 7,949 (34.6) & 3,519 (35.5) & $2,673(34.2)$ & \\
\hline $8-11$ & $8,668(37.7)$ & $4,041(40.8)$ & 3,077 (39.4) & \\
\hline $12-14$ & $1,923(8.4)$ & $602(6.1)$ & $572(7.3)$ & \\
\hline$\geq 15$ & $951(4.1)$ & $275(2.8)$ & $342(4.4)$ & \\
\hline Homelessness & $524(1.9)$ & $514(4.1)$ & $220(2.2)$ & $<0.001$ \\
\hline Alcohol use & $3,720(13.6)$ & 2,375 (18.7) & 1,771 (17.4) & $<0.001$ \\
\hline Diabetes mellitus & $1,708(6.2)$ & $863(6.8)$ & $755(7.4)$ & $<0.001$ \\
\hline Drug use & $2,136(7.8)$ & 1,535 (12.1) & $1,042(10.2)$ & $<0.001$ \\
\hline Mental disorder & $407(1.5)$ & $252(2.0)$ & $290(2.9)$ & $<0.001$ \\
\hline \multicolumn{5}{|l|}{ HIV status } \\
\hline Negative & 21,353 (77.9) & $9,591(75.5)$ & $6,682(65.6)$ & \multirow{3}{*}{$<0.001$} \\
\hline Positive & $2,417(8.8)$ & $1,281(10.1)$ & $2,187(21.5)$ & \\
\hline Unknown & 3,645 (13.3) & $1,824(14.4)$ & 1,315 (12.9) & \\
\hline $\begin{array}{l}\text { Immunosuppression from etiologies other } \\
\text { than HIV infection }\end{array}$ & $169(0.6)$ & $113(0.9)$ & $284(2.8)$ & $<0.001$ \\
\hline
\end{tabular}

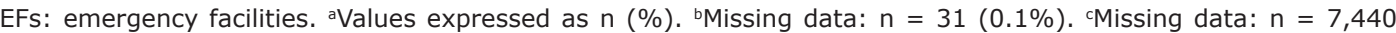
(14.8\%). ${ }^{d}$ Missing data: $n=6,388$ (12.7\%). eMissing data: $n=9,591(19.1 \%)$.

\section{DISCUSSION}

In the present population-based study of data regarding the state of São Paulo, one in every four tuberculosis patients was found to have been diagnosed in EFs. The likelihood of poor outcomes, including death and loss to follow-up, was found to be higher in the patients diagnosed in EFs than in those diagnosed in an outpatient setting. At the municipal level, structural and socioeconomic factors were found to be associated with a higher probability of being diagnosed in EFs.
Our study shows that tuberculosis remains a public health challenge and that there is a need for improving the process of diagnosing tuberculosis in the public health system. ${ }^{(1,14)}$ The proportion of patients diagnosed with tuberculosis in EFs was found to be high, despite the fact that the state of São Paulo is one of the wealthiest in the country and the fact that tuberculosis treatment is provided free of charge in Brazil. This might be due to difficult access to health care, which results in delayed diagnosis and affects 
Table 2. Characteristics of tuberculosis and tuberculosis treatment, by place of diagnosis, among patients newly diagnosed with tuberculosis in the state of São Paulo, Brazil, in the period between January of 2010 and December of 2013. ${ }^{a}$

\begin{tabular}{|c|c|c|c|c|}
\hline Variable & $\begin{array}{c}\text { Primary care/ } \\
\text { outpatient setting } \\
\text { ( } n=27,415)\end{array}$ & $\begin{array}{c}\text { EFs } \\
(n=12,696)\end{array}$ & $\begin{array}{c}\text { During } \\
\text { hospitalization } \\
(n=10,184)\end{array}$ & $\mathbf{p}$ \\
\hline \multicolumn{5}{|l|}{ Anatomical classification } \\
\hline PTB & $22,758(83.0)$ & $10,314(81.2)$ & 5,895 (57.9) & \multirow{3}{*}{$<0.001$} \\
\hline PTB + EPTB & $524(1.9)$ & $371(2.9)$ & $653(6.4)$ & \\
\hline EPTB & $3,754(13.7)$ & $1,684(13.3)$ & $3,015(29.6)$ & \\
\hline Miliary/disseminated TB & $379(1.4)$ & $327(2.6)$ & $621(6.1)$ & \\
\hline \multicolumn{5}{|l|}{ Microbiological status } \\
\hline A positive microbiological test result & $19,018(69.4)$ & $9,578(75.4)$ & $5,674(55.7)$ & $<0.001$ \\
\hline $\begin{array}{l}\text { A positive microbiological test result for } \\
\text { a pulmonary form (PTB/PTB + EPTB) }\end{array}$ & $18,289(78.6)$ & $9,103(85.2)$ & $4,873(74.4)$ & $<0.001$ \\
\hline Positive sputum smear at diagnosis ${ }^{\mathrm{b}}$ & $16,162(74.2)$ & $8,548(84.4)$ & $4,097(70.5)$ & $<0.001$ \\
\hline Positive sputum culture at diagnosis ${ }^{c}$ & $6,017(63.5)$ & $2,411(65.7)$ & $1,525(61.1)$ & $<0.001$ \\
\hline \multicolumn{5}{|l|}{ Chest X-ray ${ }^{d}$} \\
\hline Not performed & 2,998 (11.4) & $848(6.9)$ & $957(9.9)$ & \multirow{5}{*}{$<0.001$} \\
\hline Normal & $2,134(8.1)$ & $602(4.9)$ & $1,066(11.0)$ & \\
\hline Additional pathology & $177(0.7)$ & $118(1.0)$ & $192(2.0)$ & \\
\hline Suspected TB & $15,829(60.4)$ & $8,344(68.1)$ & $6,211(64.1)$ & \\
\hline Suspected TB + cavitation & $5,087(19.4)$ & $2,336(19.1)$ & $1,263(13.0)$ & \\
\hline \multicolumn{5}{|l|}{ Initial drug regimen } \\
\hline Other & $848(3.1)$ & $373(2.9)$ & $406(4.0)$ & \multirow[t]{2}{*}{$<0.001$} \\
\hline RHZE & $26,567(96.9)$ & $12,323(97.1)$ & $9,778(96.0)$ & \\
\hline Directly observed treatment & $18,872(69.1)$ & $9,120(72.4)$ & $6,466(64.0)$ & $<0.001$ \\
\hline
\end{tabular}

EFs: emergency facilities; TB: tuberculosis; PTB: pulmonary TB; EPTB: extrapulmonary TB; and RHZE: rifampin,

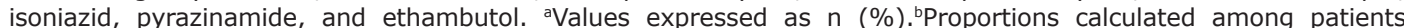
undergoing sputum collection $(n=37,717 / 40,515 ; 93 \%)$. 'Proportions calculated among patients undergoing sputum collection and culture $(n=15,638 / 40,515 ; 39 \%)$. dMissing data: $n=2,133(4.2 \%)$. eMissing data: $n=290 ;(0.6 \%)$.

treatment outcomes, as well as increasing the risk of transmission in the population and costs to the health care system. ${ }^{(14,19,21,27)}$

A diagnosis of tuberculosis in EFs is associated with

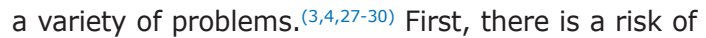
transmission to other patients, given the high prevalence of patients with pulmonary tuberculosis and positive sputum smears in contact with ill patients in a crowded area. ${ }^{(30)}$ Second, given the intrinsic characteristics of the care delivered in EFs, the possibility of tuberculosis is unlikely to be raised, thus increasing the delay in initiating appropriate treatment. ${ }^{(4)}$ Third, tuberculosis patients who are diagnosed in EFs are at a high risk of loss to follow-up because EF patients must be referred to primary care clinics. In addition, the underlying reasons for an EF diagnosis of tuberculosis-including patient vulnerability, lack of access to health care, and lack of self-awareness-potentiate the risk of loss to follow-up. (21) Health care systems should develop strategies to facilitate the retention of tuberculosis patients diagnosed in the EFs, including internet-based scheduling of visits, mobile reminders, and direct communication between hospitals and primary care clinics.

Given that tuberculosis is a chronic disease, early diagnosis and treatment (in an outpatient setting) are preferred over a diagnosis in EFs. This reinforces the importance of improving the screening of individuals with respiratory symptoms, as well as reinforcing the importance of active case finding and contact tracing. ${ }^{(1,14,31-33)}$ In addition, the level of population awareness of tuberculosis should be raised. A Brazilian soccer player has recently participated in a Brazilian national campaign against tuberculosis, the campaign being an example of how to increase population awareness and knowledge of tuberculosis and, consequently, reduce the stigma associated with the disease. ${ }^{(34)}$ However, at the municipal level, low primary care coverage was found to be associated with a higher likelihood of being diagnosed in EFs. Therefore, it is imperative to improve primary care coverage. ${ }^{(19)}$ In addition, primary care clinics must have adequate infrastructure and trained staff for tuberculosis diagnosis and treatment, the lack of adequate infrastructure and trained staff having been reported as problems in studies investigating the pathway to tuberculosis diagnosis in Brazil. $(27,29,35)$ Although we have no data as to whether EFs are equipped to diagnose tuberculosis, we speculate that a large proportion of EFs in the country have a laboratory and an X-ray machine, either on site or elsewhere (i.e., at a referral site).

In the present study, treatment outcomes were found to be worse in the patients who had been diagnosed in EFs or in a hospital setting than in those who had been diagnosed in an outpatient setting. ${ }^{(20)}$ We found that it was possible to divide the patients who had been diagnosed in EFs into three groups: socially vulnerable patients, patients with known 
Who are the patients with tuberculosis who are diagnosed in emergency facilities?

An analysis of treatment outcomes in the state of São Paulo, Brazil

Table 3. Logistic regression models for the association between place of diagnosis and tuberculosis treatment outcomes.

Unsuccessful treatment

Death

\begin{tabular}{|c|c|c|c|c|}
\hline \multicolumn{5}{|l|}{ Sample as a whole } \\
\hline & $\begin{array}{c}\text { Crude OR } \\
(95 \% \mathrm{CI})\end{array}$ & $\begin{array}{l}\text { Adjusted OR } \\
\quad(95 \% \mathrm{Cl})\end{array}$ & $\begin{array}{c}\text { Crude OR } \\
(95 \% \mathrm{CI})\end{array}$ & $\begin{array}{l}\text { Adjusted OR } \\
\quad(95 \% \mathrm{Cl})\end{array}$ \\
\hline Primary care/outpatient setting & 1 (Reference) & 1 (Reference) & 1 (Reference) & 1 (Reference) \\
\hline EFs & $\begin{array}{c}1.87(1.77-1.97) \\
p<0.001\end{array}$ & $\begin{array}{c}1.54(1.42-1.66) \\
p<0.001\end{array}$ & $\begin{array}{c}2.88(2.65-3.14) \\
p<0.001\end{array}$ & $\begin{array}{c}2.75(2.40-3.16) \\
p<0.001\end{array}$ \\
\hline During hospitalization & $\begin{array}{c}2.26(2.14-2.39) \\
p<0.001\end{array}$ & $\begin{array}{c}1.78(1.63-1.94) \\
p<0.001\end{array}$ & $\begin{array}{c}5.12(4.72-5.56) \\
p<0.001\end{array}$ & $\begin{array}{c}3.88(3.40-4.43) \\
p<0.001\end{array}$ \\
\hline \multicolumn{5}{|l|}{ HIV-negative patients } \\
\hline & $\begin{array}{c}\text { Crude OR } \\
(95 \% \mathrm{CI})\end{array}$ & $\begin{array}{l}\text { Adjusted OR } \\
(95 \% \mathrm{Cl})\end{array}$ & $\begin{array}{c}\text { Crude OR } \\
(95 \% \mathrm{CI})\end{array}$ & $\begin{array}{l}\text { Adjusted OR } \\
(95 \% \mathrm{Cl})\end{array}$ \\
\hline Primary care/outpatient setting & 1 (Reference) & 1 (Reference) & 1 (Reference) & 1 (Reference) \\
\hline EFs & $\begin{array}{c}1.60(1.49-1.72) \\
p<0.001\end{array}$ & $\begin{array}{c}1.33(1.20-1.46) \\
p<0.001\end{array}$ & $\begin{array}{c}2.44(2.15-2.78) \\
p<0.001\end{array}$ & $\begin{array}{c}2.36(1.95-2.85) \\
p<0.001\end{array}$ \\
\hline During hospitalization & $\begin{array}{c}1.75(1.61-1.89) \\
p<0.001\end{array}$ & $\begin{array}{c}1.60(1.43-1.79) \\
p<0.001\end{array}$ & $\begin{array}{c}4.27(3.77-4.84) \\
p<0.001\end{array}$ & $\begin{array}{c}3.34(2.86-4.16) \\
p<0.001\end{array}$ \\
\hline \multicolumn{5}{|l|}{ HIV-positive patients } \\
\hline & $\begin{array}{c}\text { Crude OR } \\
(95 \% \mathrm{Cl})\end{array}$ & $\begin{array}{l}\text { Adjusted OR } \\
\qquad(95 \% \mathrm{Cl})\end{array}$ & $\begin{array}{c}\text { Crude OR } \\
(95 \% \mathrm{Cl})\end{array}$ & $\begin{array}{l}\text { Adjusted OR } \\
\qquad(95 \% \mathrm{Cl})\end{array}$ \\
\hline Primary care/outpatient setting & 1 (Reference) & 1 (Reference) & 1 (Reference) & 1 (Reference) \\
\hline EFs & $\begin{array}{c}2.43(2.11-2.80) \\
p<0.001\end{array}$ & $\begin{array}{c}1.97(1.59-2.44) \\
p<0.001\end{array}$ & $\begin{array}{c}3.52(2.94-4.20) \\
p<0.001\end{array}$ & $\begin{array}{c}3.45(2.58-4.61) \\
p<0.001\end{array}$ \\
\hline During hospitalization & $\begin{array}{c}2.05(1.83-2.34) \\
p<0.001\end{array}$ & $\begin{array}{c}1.78(1.48-2.15) \\
p<0.001\end{array}$ & $\begin{array}{c}3.48(2.97-4.09) \\
p<0.001\end{array}$ & $\begin{array}{c}3.63(2.80-4.71) \\
p<0.001\end{array}$ \\
\hline
\end{tabular}

EFs: emergency facilities. ${ }^{a}$ Adjusted for age, sex, country of birth, self-reported ethnicity, level of education, homelessness, alcohol use, drug use, diabetes mellitus, mental disorder, HIV status, immunosuppression from etiologies other than HIV infection, anatomical classification, microbiological diagnosis, chest X-ray findings at diagnosis, initial drug treatment, and directly observed treatment. 'bdjusted for age, sex, country of birth, selfreported skin color/ethnicity, level of education, homelessness, alcohol use, drug use, diabetes mellitus, mental disorder, immunosuppression from etiologies other than HIV infection, anatomical classification, microbiological diagnosis, chest X-ray findings at diagnosis, initial drug treatment, and directly observed treatment.

Table 4. Structural and socioeconomic indicators aggregated at the municipal level and associated with tuberculosis diagnosis in emergency facilities.

\begin{tabular}{|c|c|c|c|c|c|}
\hline \multirow[t]{2}{*}{ Indicator } & \multicolumn{2}{|l|}{ Model 1} & \multirow[t]{2}{*}{ Indicator } & \multicolumn{2}{|l|}{ Model 2} \\
\hline & OR (95\% CI) & p & & OR (95\% CI) & $\mathbf{p}$ \\
\hline $\begin{array}{l}\text { Primary care coverage } \\
\text { (1\% increase) }\end{array}$ & $0.997(0.995-0.998)$ & $<0.001$ & $\begin{array}{c}\text { Primary care coverage } \\
\text { (1\% increase) }\end{array}$ & $0.998(0.997-0.999)$ & 0.002 \\
\hline $\begin{array}{l}\text { IDH } \\
\text { (1\% increase) }\end{array}$ & $0.936(0.926-0.947)$ & $<0.001$ & & & \\
\hline $\begin{array}{l}\text { Gini coefficient } \\
\text { (1\% increase) }\end{array}$ & $1.036(1.030-1.041)$ & $<0.001$ & $\begin{array}{l}\text { Highly vulnerable population }{ }^{\mathrm{a}} \\
\text { ( } 1 \% \text { increase })\end{array}$ & $1.018(1.016-1.020)$ & $<0.001$ \\
\hline $\begin{array}{l}\text { Urbanization } \\
\text { (1\% increase) }\end{array}$ & $1.032(1.026-1.037)$ & $<0.001$ & & & \\
\hline $\begin{array}{l}\text { Population density } \\
\left(100 / \mathrm{km}^{2} \text { increase }\right)\end{array}$ & $1.001(1.000-1.002)$ & 0.036 & $\begin{array}{l}\text { Population density } \\
\left(100 / \mathrm{km}^{2} \text { increase) }\right.\end{array}$ & $1.005(1.005-1.006)$ & $<0.001$ \\
\hline
\end{tabular}

IDH: Índice de Desenvolvimento Humano (Human Development Index). aAs determined by the 2010 version of the Índice Paulista de Vulnerabilidade Social (IPVS, São Paulo State Social Vulnerability Index), developed by the São Paulo Sistema Estadual de Análise de Dados (SEADE, State System of Data Analysis) Foundation.(26)

chronic diseases, and patients who are young and "healthy". For each group of patients, a different set of interventions is required in order to improve their outcomes. Socially vulnerable patients usually have limited access to primary care because of their marginalization and weak social capital. ${ }^{(9,36)}$ Recent studies have shown that homeless individuals commonly seek EF treatment for diseases at an advanced stage. ${ }^{(37)}$
To tackle this group of patients, the health community should focus on specific goals, including mobile health care clinics, ${ }^{(33,38)}$ active case finding in shelters, ${ }^{(33)}$ and, fundamentally, a multidisciplinary political and societal approach. ${ }^{(9,36)}$ There is a need for improving socioeconomic indicators and advocating government actions that have been shown to be effective, such as conditional cash transfers. ${ }^{(39)}$ 

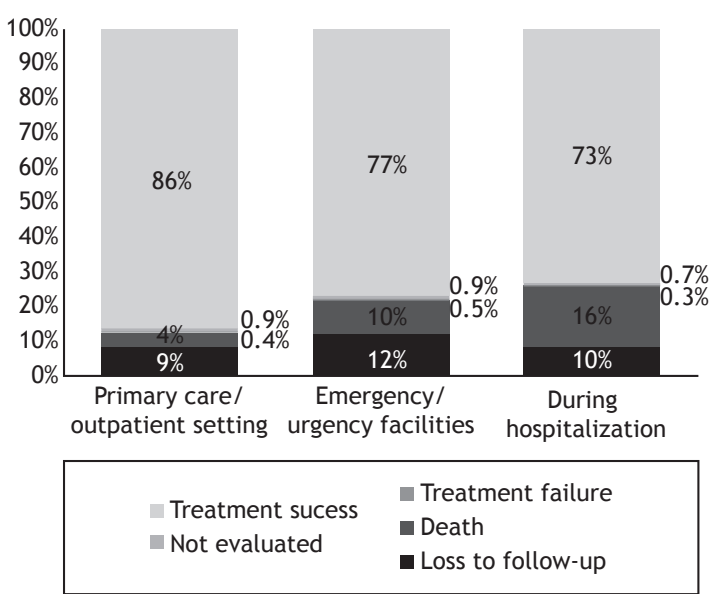

Figure 1. Tuberculosis treatment outcomes stratified by place of diagnosis.

Patients with known chronic diseases have a close relationship with the health care system. Our hypothesis is that such patients commonly have severe clinical presentations of tuberculosis or present with chronic disease exacerbations caused by tuberculosis, posing additional challenges for the diagnosis of tuberculosis and requiring a different approach (e.g., invasive procedures).(20) One expected limitation of studies such as ours (i.e., studies of secondary data) is the lack of detailed information on the degree of disease severity and the diagnostic process in such patients to determine whether they could have been diagnosed outside the hospital setting. Further studies are needed in order to gain a better understanding of this group of patients and provide data to inform potential interventions. Nevertheless, it is clear that we should focus on continuing tuberculosis education for health care workers at all levels of care and act to bridge the "knowledge-do gap", thus facilitating the implementation of tuberculosis guidelines in real practice. ${ }^{(40)}$

Of particular interest is the third group, which comprises young and "healthy" patients. The likely reason why such patients are diagnosed in EFs is that they live in areas where access to primary care is limited or where primary care clinics lack adequate infrastructure. $(14,19,21)$ The stigma surrounding tuberculosis management at a health care clinic in the community likely leads such patients to seek medical assistance only when the disease is at an advanced stage or to expect a rapid solution in EFs. ${ }^{(3-5,21)}$

In the present study, traditional structural and socioeconomic indicators were found to be associated with a high probability of being diagnosed in EFs. We selected four municipalities to illustrate how the aforementioned indicators can influence the place of diagnosis. The most important message is that it is not enough to assess only one indicator. Many of the municipalities in the state of São Paulo are wealthy (as evidenced by a high IDH) but have a high proportion of socially vulnerable individuals (as evidenced by a high IPVS), as well as inadequate primary care coverage. In these municipalities, we can assume that
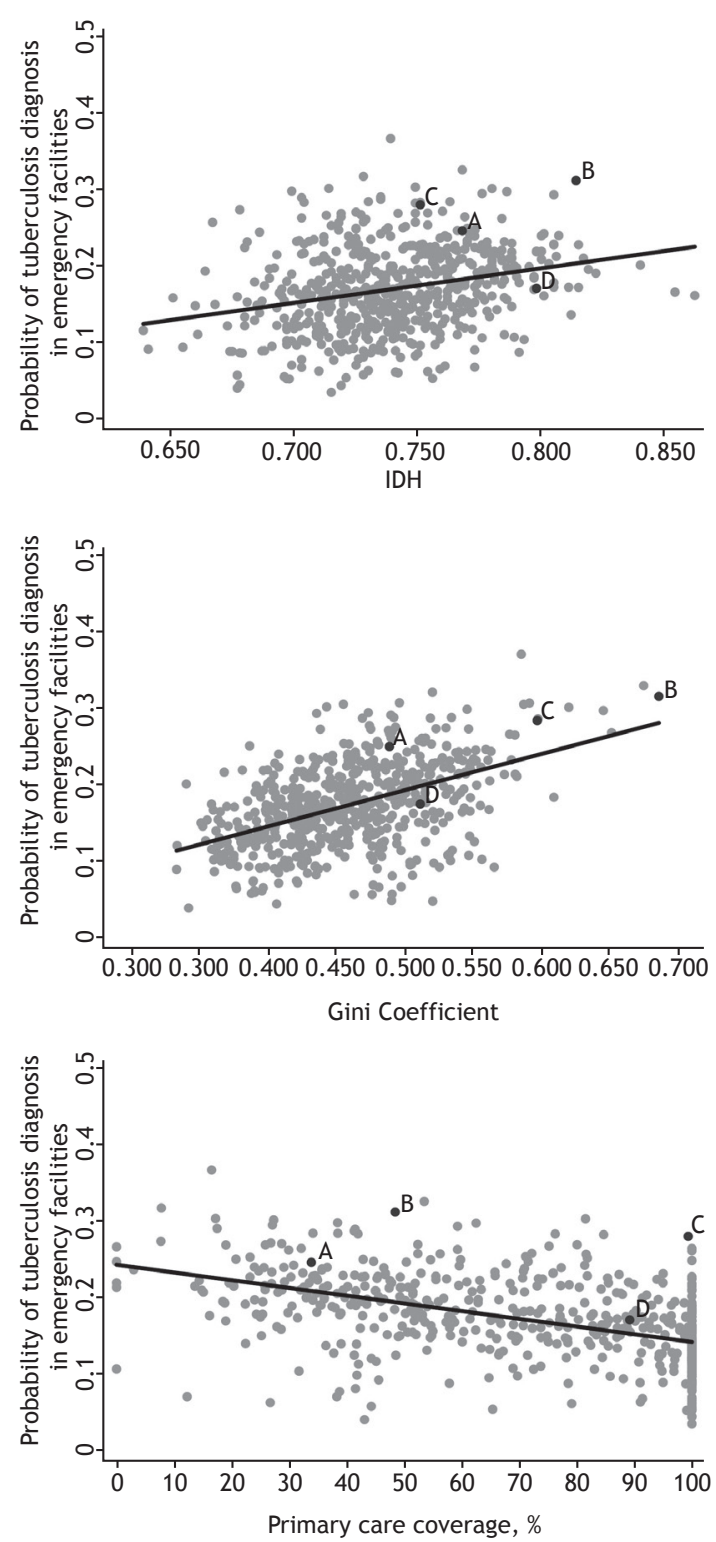

Figure 2. Relationship between municipal indicators and the probability of tuberculosis diagnosis in emergency facilities.* *The probability of tuberculosis diagnosis in emergency facilities was estimated from adjusted model 1 , on the basis of the Índice de Desenvolvimento Humano (IDH, Human Development Index), the Gini coefficient, primary care coverage, population density, and urbanization. A, B, C, and D represent the four municipalities discussed in the manuscript, the proportions of patients diagnosed in emergency facilities being $53 \%$ for A, $41 \%$ for $B, 21 \%$ for $C$, and $7 \%$ for $D$.

the richest are treated at private hospitals whereas the poorest have limited access to primary care, a factor that plays a major role in delaying the diagnosis of tuberculosis. Therefore, in order to improve tuberculosis care, it is essential to perform further analysis of each metropolitan area, municipality, and region for a tailored multifaceted intervention.

Our study has limitations that should be acknowledged. First, we analyzed data regarding one Brazilian state 
rather than the entire country. However, we do not expect to observe a different pattern at the country level regarding place of tuberculosis diagnosis. ${ }^{(19,28)}$ Second, we have no data regarding the number of health care visits before tuberculosis diagnosis or the time elapsed from symptom onset to diagnosis and treatment initiation. Third, data regarding large cities and smaller municipalities in the state were not analyzed separately, because our objective was to characterize the state of São Paulo as a whole. However, we speculate that our findings are also applicable to the large cities of the state. Finally, tuberculosis was microbiologically confirmed in $68 \%$ of all cases and in $85 \%$ of the patients who had pulmonary tuberculosis and valid sputum samples, proportions that are higher than the global average. (2) The TBweb database has a dedicated team of professionals who continuously check for consistency, and cases of patients whose initial diagnosis was changed or who were diagnosed with nontuberculous mycobacterial infection were excluded. However, we cannot exclude the possibility of misclassification. Nevertheless, this would have introduced only a minimal bias toward the null rather than a differential bias across places of diagnosis.

Although there has been a major improvement in tuberculosis control, there is a need for further improvement. In the state of São Paulo, $25 \%$ of all tuberculosis patients are diagnosed in EFs, a factor that is associated with poor treatment outcomes. At the municipal level, an EF diagnosis of tuberculosis is associated with inequality, social vulnerability, and inadequate primary care coverage, indicating areas for improvement.

\section{ACKNOWLEDGMENTS}

We are grateful to the dedicated staff of the Tuberculosis Control Department of the Prof. Alexandre Vranjac Center for Epidemiological Surveillance of the São Paulo State Department of Health for supervising the São Paulo State Tuberculosis Control Program and managing the TBweb database.

\section{REFERENCES}

1. Lönnroth K, Raviglione M. The WHO's new End TB Strategy in the post-2015 era of the Sustainable Development Goals. Trans R Soc Trop Med Hyg. 2016;110(3):148-50. https://doi.org/10.1093/trstmh/ trv108

2. World Health Organization. Global tuberculosis report 2015. Geneva: World Health Organization; 2015.

3. Almeida CP, Skupien EC, Silva DR. Health care seeking behavio and patient delay in tuberculosis diagnosis. Cad Saude Publica. 2015;31(2):321-30. https://doi.org/10.1590/0102-311X00195413

4. Miller AC, Polgreen LA, Cavanaugh JE, Hornick DB, Polgreen PM Missed Opportunities to Diagnose Tuberculosis Are Common Among Hospitalized Patients and Patients Seen in Emergency Departments. Open Forum Infect Dis. 2015;2(4):ofv171. https://doi. org/10.1093/ofid/ofv171

5. Sreeramareddy CT, Panduru KV, Menten J, Van den Ende J. Time delays in diagnosis of pulmonary tuberculosis: a systematic review of literature. BMC Infect Dis. 2009;9:91. https://doi.org/10.1186/1471 2334-9-91

6. Storla DG, Yimer S, Bjune GA. A systematic review of delay in the diagnosis and treatment of tuberculosis. BMC Public Health 2008;8:15. https://doi.org/10.1186/1471-2458-8-15

7. Sreeramareddy CT, Qin ZZ, Satyanarayana S, Subbaraman R, Pai M. Delays in diagnosis and treatment of pulmonary tuberculosis in India: a systematic review. Int J Tuberc Lung Dis. 2014;18(3):255-266. https://doi.org/10.5588/ijtld.13.0585

8. Brasil. Ministério da Saúde. Secretaria de Vigilância em Saúde. Departamento de Vigilância Epidemiológica. Manual de recomendações para o controle da tuberculose no Brasil. Brasília: Ministério da Saúde; 2011

9. Ranzani OT, Carvalho CR, Waldman EA, Rodrigues LC. The impact of being homeless on the unsuccessful outcome of treatment of pulmonary TB in Sao Paulo State, Brazil. BMC Med. 2016;14:41. https://doi.org/10.1186/s12916-016-0584-8

10. Brasil. Ministério da Saúde. Secretaria de Vigilância em Saúde. Departamento de Vigilância Epidemiológica. Boletim Epidemiológico da Secretaria de Vigilância em Saúde; 2013.

11. Lindoso AA, Waldman EA, Komatsu NK, Figueiredo SM, Taniguchi M, Rodrigues LC. Profile of tuberculosis patients progressing to death, city of São Paulo, Brazil, 2002. Rev Saude Publica. 2008;42(5):805-12 https://doi.org/10.1590/S0034-89102008000500004

12. Governo do Estado de São Paulo. Secretaria de Estado da Saúde [homepage on the Internet]. São Paulo: a Secretaria; c2015 [cited 2015 Nov 15]. Center for Disease Control (CCD). CVE - Centro de Vigilância Epidemiológica "Prof. Alexandre Vranjac". Sistemas de Informação. Available from: http://www.saude.sp.gov.br/cve-

centro-de-vigilancia-epidemiologica-prof.-alexandre-vranjac/areas-devigilancia/tuberculose/sistemas-de-informacao/

13. Portal de Estatísticas do Estado de São Paulo. Fundação Sistema Estadual de Análise de Dados [homepage on the Internet]. São Paulo: SEADE; [cited 2017 Sep 20]. Available from: http://www. seade.gov.br/

14. Popolin MP, Touso MM, Yamamura M, Rodrigues LB, da Cunha Garcia MC, Arroyo LH, et al. Integrated health service delivery networks and tuberculosis avoidable hospitalizations: is there a relation between them in Brazil? BMC Health Serv Res. 2016;16:78.

15. Coimbra I, Maruza M, Militao-Albuquerque Mde F, Moura LV, Diniz GT, Miranda-Filho Dde B, et al. Associated factors for treatment delay in pulmonary tuberculosis in HIV-infected individuals: a nested case-control study. BMC Infect Dis. 2012;12:208. https://doi. org/10.1186/1471-2334-12-208

16. dos Santos MA, Albuquerque MF, Ximenes RA, Lucena-Silva $\mathrm{NL}$, Braga C, Campelo AR, et al. Risk factors for treatment delay in pulmonary tuberculosis in Recife, Brazil. BMC Public Health. 2005;5:25. https://doi.org/10.1186/1471-2458-5-25

17. Maior Mde L, Guerra RL, Cailleaux-Cezar M, Golub JE, Conde MB. Time from symptom onset to the initiation of treatment of pulmonary tuberculosis in a city with a high incidence of the disease. J Bras Pneumol. 2012;38(2):202-9.

18. Machado AC, Steffen RE, Oxlade O, Menzies D, Kritski A, Trajman A Factors associated with delayed diagnosis of pulmonary tuberculosis in the state of Rio de Janeiro, Brazil. J Bras Pneumol. 2011;37(4):512 20. https://doi.org/10.1590/S1806-37132011000400014

19. Bartholomay P, Pelissari DM, de Araujo WN, Yadon ZE, Heldal E. Quality of tuberculosis care at different levels of health care in Brazi in 2013. Rev Panam Salud Publica. 2016;39(1):3-11.

20. Perrechi MC, Ribeiro SA. Outcomes of tuberculosis treatment among inpatients and outpatients in the city of Sao Paulo, Brazil. J Bras Pneumol. 2011;37(6):783-90. https://doi.org/10.1590/S180637132011000600012

21. Deponti GN, Silva DR, Coelho AC, Muller AM, Dalcin Pde T. Delayed diagnosis and associated factors among new pulmonary tuberculosis patients diagnosed at the emergency department of a tertiary care hospital in Porto Alegre, South Brazil: a prospective patient recruitment study. BMC Infect Dis. 2013;13:538. https://doi. org/10.1186/1471-2334-13-538

22. World Health Organization. Definitions and reporting framework for tuberculosis - 2013 revision. Geneva: World Health Organization; 2013.

23. Galesi VM. Data on tuberculosis in the state of São Paulo, Brazi [Article in Portuguese]. Rev Saude Publica. 2007;41 Suppl 1:121. 
https://doi.org/10.1590/S0034-89102007000800017

24. Instituto Brasileiro de Geografia e Estatística [homepage on the Internet]. São Paulo: IBGE; c2016 [cited 2016 Nov 15]. Censo Demográfico 2010; [about 3 screens]. Available from: https://www. ibge.gov.br/estatisticas-novoportal/sociais/populacao/9662-censodemografico-2010.html?\&t=o-que-e

25. Brasil. Ministério da Saúde. Departamento de Atenção Básica. Secretaria de Atenção à Saúde [homepage on the Internet]. Brasília: o Ministério; [cited 2017 Oct 3]. e-Gestor-Cobertura da Atenção Básica; [about 2 screens]. Available from: https://egestorab.saude. gov.br/paginas/acessoPublico/relatorios/relHistoricoCoberturaAB. xhtml

26. Portal de Estatísticas do Estado de São Paulo. Fundação Sistema Estadual de Análise de Dados [homepage on the Internet]. São Paulo: SEADE; [cited 2017 Oct 3]. Índice Paulista de Vulnerabilidade Social, versão 2010. [Adobe Acrobat document, 18p.]. Available from: http:// indices-ilp.al.sp.gov.br/view/pdf/ipvs/metodologia.pdf

27. de Oliveira MF, Arcencio RA, Ruffino-Netto A, Scatena LM, Palha PF, Villa TC. The front door of the Ribeirao Preto health system for diagnosing tuberculosis [Article in Portuguese]. Rev Esc Enferm USP. 2011;45(4):898-904.

28. Loureiro RB, Villa TC, Ruffino-Netto $A$, Peres RL, Braga JU, Zandonade $\mathrm{E}$, et al. Access to the diagnosis of tuberculosis in health services in the municipality of Vitoria, state of Espírito Santo, Brazi [Article in Portuguese]. Cien Saude Colet. 2014:19(4):1233-44. https://doi.org/10.1590/1413-81232014194.01002013

29. Ponce MA, Wysocki AD, Scatolin BE, Andrade RL, Arakawa $T$, Ruffino Netto $A$, et al. Tuberculosis diagnosis and performance assessment of the first health service used by patients in São José do Rio Preto, São Paulo State, Brazil [Article in Portuguese]. Cad Saude Publica. 2013;29(5):945-54. https://doi.org/10.1590/S0102311X2013000500012

30. Escombe AR, Huaroto L, Ticona E, Burgos M, Sanchez I, Carrasco $L$, et al. Tuberculosis transmission risk and infection control in a hospital emergency department in Lima, Peru. Int J Tuberc Lung Dis. 2010;14(9):1120-6.

31. Pai M, Behr MA, Dowdy D, Dheda K, Divangahi M, Boehme CC, et al. Tuberculosis. Nat Rev Dis Primers. 2016;2:16076. https://doi. org/10.1038/nrdp.2016.76

32. Jiménez-Fuentes MA, Augé CM, Gómez MN, Peiró JS, de Souza Galvão ML, Maldonado J, et al. Screening for active tuberculosis in high-risk groups. Int J Tuberc Lung Dis. 2014;18(12):1459-65. https:// doi.org/10.5588/ijtld.14.0271

33. Story A, Aldridge RW, Abubakar I, Stagg HR, Lipman M, Watson JM et al. Active case finding for pulmonary tuberculosis using mobile digital chest radiography: an observational study. Int J Tuberc Lung Dis. 2012;16(11):1461-7. https://doi.org/10.5588/ijtld.11.0773

34. YouTubeBR [homepage on the Internet]. San Bruno (CA): YouTube; [cited 2017 Oct 3]. Ministry of Health - Brazil. Campanha Contra a Tuberculose | Filme Oficial 2015. Available from: https://www. youtube.com/watch? $v=$ LCLfSQ_BDol

35. Paula Rd, Lefevre F, Lefevre AM, Galesi VM, Schoeps D. Why do tuberculosis patients look for urgency and emergency unities for diagnosis: a study on social representation. Rev Bras Epidemiol. 2014;17(3):600-14. https://doi.org/10.1590/1809-4503201400030003

36. Hwang SW, Tolomiczenko G, Kouyoumdjian FG, Garner RE. Interventions to improve the health of the homeless: a systematic review. Am J Prev Med. 2005;29(4):311-9. https://doi.org/10.1016/j. amepre.2005.06.017

37. D'Amore J, Hung O, Chiang W, Goldfrank L. The epidemiology of the homeless population and its impact on an urban emergency department. Acad Emerg Med. 2001:8(11):1051-5. https://do . org/10.1111/j.1553-2712.2001.tb01114.x

38. Hallais JA, Barros NF. Street Outreach Offices: Visibility, invisibility and enhanced visibility [Article in Portuguese]. Cad Saude Publica. 2015;31(7):1497-504. https://doi.org/10.1590/0102-311X00143114

39. Torrens AW, Rasella D, Boccia D, Maciel EL, Nery JS, Olson ZD, et al. Effectiveness of a conditional cash transfer programme on TB cure rate: a retrospective cohort study in Brazil. Trans R Soc Trop Med Hyg. 2016;110(3):199-206. https://doi.org/10.1093/trstmh/trw011

40. Datta S, Saunders MJ, Tovar MA, Evans CA. Improving tuberculosis diagnosis: Better tests or better healthcare? PLoS Med. 2017;14(10):e1002406. https://doi.org/10.1371/journal. pmed.1002406 